\title{
Primary care providers' experiences treating low back pain
}

https://doi.org/10.1515/jom-2021-0229

Received September 15, 2021; accepted December 16, 2021; published online February 7, 2022

\section{Abstract}

Context: Our original work addresses the biological sex impact on low back pain (LBP) management and prognosis in primary care settings. To our knowledge, our study is the first in the United States to evaluate the differences in clinicians' approaches to LBP in the ambulatory setting specifically based on patient gender. Our findings suggest that there is a knowledge gap among primary care providers (PCPs) toward the potential impact of biological sex on LBP and a bias toward gender roles when counseling patients for home chores or occupational tasks. Further evaluation of this knowledge gap and its impact on LBP management and prognosis is recommended in US healthcare settings. Objectives: This study aims to explore PCP experiences and practice patterns regarding LBP in females compared to males in US healthcare settings.

Methods: We utilized a cross-sectional study design and convenience sampling. Data were collected anonymously utilizing a 27-item online survey sent periodically via email to PCPs working in Ohio. We had 58 responses for analysis; data were analyzed utilizing bivariate and multivariate analyses.

Results: On average, approximately 9 out of 10 responding clinicians reported experiencing LBP. PCPs were not in agreement that LBP is different in women than men. Clinicians with a women's health, osteopathic, or sport's medicine background were more likely to agree that LBP is different in women than in men. PCPs were more likely to counsel female patients about pelvic floor exercises; however, their intake of present pelvic symptoms in LBP female

*Corresponding author: Sondos Al Sad, MD, MPH, The Ohio State University College of Medicine, 468 Prior Hall, 376 West 10th Avenue, Columbus, OH 43210, USA, E-mail: alsad.sondos@gmail.com. https://orcid.org/0000-0003-0512-6924

Amanda R. Start, PhD, The Ohio State University College of Medicine Office of Curriculum and Scholarship, Columbus, OH, USA.

https://orcid.org/0000-0002-9290-5522 patients is suboptimal. PCPs were more likely to counsel females for home chores than males, which is aligned with the perceived traditional gender roles among PCPs.

Conclusions: There may be a knowledge gap among PCPs toward the potential impact of biological sex on LBP and a bias toward gender roles when counseling patients for home chores or occupational tasks. Further investigation of this knowledge gap and counseling approaches is recommended to better bridge the gender disparity.

Keywords: clinical experts; gender impact; low back pain.

Low back pain (LBP) is one of the most common health concerns encountered in the ambulatory setting [1, 2], a main cause of physical disability in people below the age of 45 years [3], activity limitation [4], and work absence [5, 6]. The Global Burden of Disease (GBD) Study, published at the end of 2019, has highlighted the enormous global burden of LBP. In contrast to the GBD study in 2000, when LBP was ranked 105 out of 136 conditions, LBP remains the leading cause of disability globally, ahead of 290 other conditions $[7,8]$. LBP can be nonspecific, which is most encountered in primary care settings for further evaluation, or specific (i.e., mechanical with identifiable structural pathology) [4, 9]. However, research defining LBP as a disease or episodic, acute or chronic, and first episode or recurrent has been suboptimal [9]. Most people who experience activity-limiting LBP go on to have recurrent episodes; estimates of one-year recurrence range from $24 \%$ to $80 \%$ [10]. Nevertheless, LBP is often regarded as a trivial problem compared to other chronic medical conditions and has been relatively underprioritized and underfunded $[5,8]$. LBP treatment guidelines have improved costeffectiveness and have established limitations on opioid use, yet they are challenged in quality and consistency [11] and do not include patients' preferences and sociodemographic characteristics $[12,13]$.

Although biological sex is recognized as an important determinant of health and an important moderating factor in healthcare-related research, it is not specifically accounted for in the clinical assessment of many illnesses, including LBP $[14,15]$. Although the pathogenesis of LBP stems from 
shared basic mechanisms in its acute phase, it is confounded by aging [16], the patient's gender, and social determinants of health variables [17]. Current biopsychosocial evidence suggests that women and men experience chronic LBP differently [18-20], yet this difference is not mirrored in its clinical evaluation and management. In adult women, hormonal and reproductive factors are associated with chronic musculoskeletal pain in general [14, 21]. Specifically, factors related to increased estrogen levels may increase the risk of chronic LBP [14, 20]. Other studies show how LBP is further complicated by the prevalence of concurrent pelvic floor dysfunction in many women, demonstrating that there are implications of LBP beyond the musculoskeletal system [22]. Although the overall prevalence of back pain is minimal between the ages of 25 and 35 years, the incidence of nonspecific LBP is high in women of that reproductive age [23]. Compared to men, women are found to be more severely affected by LBP and often carry a worse prognosis [17, 24]. A longitudinal study of chronic LBP in 351 patients, conducted at metropolitan clinics in Chicago over 2 years, showed that retired women reported more pain than retired men, and marriage was associated with more household work for women and less for men [24]. The study suggested that sex differences in adaptive functioning were consistent with traditional gender roles, and the treatment of women with chronic LBP requires attention to work in the home and the financial and social context to work outside the home [24, 25].

Women tend to perceive LBP as normal in various stages of their lives (e.g., menstruation or gestation [26]), which may have serious implications on morbidity, including delayed reporting, unsafe self-management, or masking other pathologies [27]. Qualitative studies reported that women received limited advice and support from healthcare professionals and perceived them as being dismissive, uninformative, and lacking knowledge about LBP during pregnancy, resulting in many women feeling unsupported and left to do their own research on their pain [28].

Despite the updates in guidelines for LBP, its management remains challenging with significant gaps and variabilities among primary care providers (PCPs) globally $[29,30]$. Assessing current primary care approaches to LBP in women of reproductive age is critical given the significant impact on healthcare costs as well as disability and quality of life [31].

Our study aims to assess and survey current PCPs' approaches and attitudes toward LBP management in the United States to further develop population-based guidelines addressing the sex differences in this crippling health problem.

\section{Methods}

Our cross-sectional study was deemed exempt by The Ohio State University (OSU) Institutional Review Board. Informed consent was included in the online survey.

We created an anonymous, 27-item online survey (see Appendix A). We provided respondents a definition of LBP and, where relevant, provided contextual information to ensure a consistent approach for answering survey questions. For the purpose of the survey, we referred to LBP as an "initial encounter with low (lumbosacral) back pain with no current imaging." For the questions regarding diagnosis, we provided the following context:

- What is the most frequent diagnosis you use for low back pain in non-pregnant females of reproductive age without red flags (e.g., muscle atrophy, radiculopathy, pain severity $>8 / 10$, weight loss) or prior imaging?

- What is the most frequent diagnosis you use for low back pain in male patients of reproductive age without red flags (e.g., muscle atrophy, radiculopathy, pain severity $>8 / 10$, weight loss) or prior imaging?

We surveyed a convenience sample of 231 Family Medicine (FM), Internal Medicine (IM) and Obstetrics and Gynecology (OBGYN) clinicians, residents, and fellows associated with OSU. We utilized Qualtrics (Qualtrics, Provo, UT, 2020) to manage survey dissemination. We sent seven monthly emails to the listserv from June 2020 to December 2020. Because we collected the data anonymously, all reminders were sent to the entire listserv, regardless of participation.

\section{Analysis plan}

We conducted a series of chi-square and Fisher's Exact tests to evaluate the degree to which respondents' age ( $>45 \mathrm{vs.} 46$ or older), years of experience (10 or fewer years vs. more than 10 years), or specialty (women's health, sports medicine, and osteopathic manipulation vs. other) varied by gender (male vs. female). We conducted a series of t-tests to assess the differences in clinicians' beliefs about the impact of patient gender on LBP based on the clinicians' gender, years of experience, specialty, and previous personal experience with LBP. We then calculated t-tests (assumption of normality satisfied) or MannWhitney $\mathrm{U}$ tests (assumption of normality violated) to assess the differences in clinicians' history-taking and LBP management based on patient gender. Finally, we estimated a McNemar Test to assess differences in the proportions of providers utilizing an LBP or other diagnosis for male vs. female patients. All hypothesis testing was twosided (alpha $=0.05$ ). We conducted statistical analyses utilizing IBM SPSS version 26.

\section{Results}

\section{Participants}

We had 58 responses available for analysis, representing a response rate of $25.1 \%$. Most of our respondents were females $(n=39,67.2 \%)$, younger than 45 years of age $(n=39$, $67.2 \%)$, in clinical practice for less than 10 years $(n=33$, 
Table 1: Respondent demographics.

\begin{tabular}{lrr}
\hline Demographic & Frequency & Percent \\
\hline Gender & & \\
$\quad$ Male & 19 & $33 \%$ \\
Female & 39 & $67 \%$ \\
Age & & \\
$\leq 45$ years & 39 & $67 \%$ \\
$>45$ years & 19 & $33 \%$ \\
Years of clinical practice & & \\
$\leq 10$ years & 33 & $57 \%$ \\
$>10$ years & 25 & $43 \%$ \\
Race & & \\
White & 45 & $78 \%$ \\
Asian & 6 & $10 \%$ \\
Black or African American & 4 & $7 \%$ \\
Middle Eastern/North African & 1 & $2 \%$ \\
Other & 2 & $3 \%$ \\
Type of practice & & \\
Academic & 53 & $91 \%$ \\
Private & 3 & $5 \%$ \\
Other & 2 & $3 \%$ \\
Clinical interests (check all that apply) & & \\
Women's health, sports medicine, & 19 & $29 \%$ \\
osteopathic manipulation & & \\
Other & 46 & $71 \%$ \\
\hline
\end{tabular}

$56.9 \%)$, and working in an academic setting $(n=53,91.4 \%)$. Of interest, almost 9 out of 10 respondents reported personally experiencing LBP at some point $(n=50,86.2 \%$; Table 1).

We identified no significant differences in respondents' age $(\mathrm{p}=0.767)$, years of clinical practice $(\mathrm{p}=0.779)$, type of practice $\left(\chi^{2}[2]=2.667 ; p=0.264\right)$, clinical interests $(p=1.00)$, or previous experience with LBP $(p=1.00)$ based on their gender.

\section{Beliefs about impact of gender on LBP}

One in four ( $\mathrm{n}=15,25.8 \%)$ clinicians disagreed that LBP is different between female and male patients, 1 in $3(n=19$, $32.8 \%$ ) were neutral about a difference, and only 2 in 5 $(n=24,41.4 \%)$ agreed that LBP was different for female and male patients. We observed a nonsignificant trend for specialty $(\mathrm{t}[56]=-1.868, \mathrm{p}=0.067, \mathrm{~d}=0.67)$. Clinicians with interests in women's health, sports medicine, and osteopathic manipulation $(n=17,29.3 \%)$ tended to agree more on the impact of gender on LBP $(M=3.53, S D=1.07)$ compared to clinicians with other clinical interests $(n=41,70.6 \%$; $\mathrm{M}=3.02, \mathrm{SD}=0.14)$. We observed no significant differences based on clinician gender $(\mathrm{t}[56]=-0.08, \mathrm{p}=0.937$; female: $\mathrm{n}=39$ [67.2\%], $\mathrm{M}=3.18, \mathrm{SD}=0.97$; male: $\mathrm{n}=19$ [32.8\%], $\mathrm{M}=3.16, \mathrm{SD}=0.96)$, years of clinical experience $(\mathrm{t}[56]=0.915$, $\mathrm{p}=0.364 ; 10$ or fewer years: $\mathrm{n}=33[\%], \mathrm{M}=3.27, \mathrm{SD}=0.98$; more than 10 years: $n=25$ [\%], $M=3.04, S D=0.94)$, or previous personal experience of LBP $(\mathrm{t}[56]=0.15, \mathrm{p}=0.882$; previous LBP: $\mathrm{n}=50$ [86.2\%], $\mathrm{M}=3.18, \mathrm{SD}=0.98$; no previous LBP: $\mathrm{n}=8$ [13.8\%], $\mathrm{M}=3.13, \mathrm{SD}=0.84)$.

\section{Approaches to history and management}

We found that less than half of the clinicians reported that they would "always" or "often" inquire about OBGYN history ( $\mathrm{n}=27,47.4 \%$; $\mathrm{M}=3.47, \mathrm{SD}=1.07)$, confirm contraception prior to prescribing analgesics for LBP $(n=25$, 43.1\%, $\mathrm{M}=3.28, \mathrm{SD}=1.34$ ), or ask about menstrual symptoms with LBP ( $\mathrm{n}=25,43.1 \% ; \mathrm{M}=3.33, \mathrm{SD}=1.05)$. In general, clinicians reported that they infrequently counseled patients about pelvic floor exercises $(M=1.97, S D=1.15)$. Of note, two in five clinicians $(n=23,43.1 \%)$ reported that they would ask less often about pelvic floor symptoms for females with LBP $(\mathrm{M}=3.59, \mathrm{SD}=1.08)$.

Clinicians reported more frequently counseling female patients (Mean Rank=68.16; $M=2.29, S D=1.19$ ) about pelvic floor exercises than male patients (Mean Rank=47.67; $\mathrm{M}=1.65, \mathrm{SD}=1.03 ; \mathrm{U}=1064.00, \mathrm{p}<0.001)$. Although marginally significant, clinicians also reported a trend to more frequently counsel female patients $(M=3.71, S D=0.99)$ about the impact of home chores compared to male patients $(\mathrm{M}=3.34, \mathrm{SD}=1.05$; $\mathrm{t}[114]=-1.907, \mathrm{p}=0.059, \mathrm{~d}=0.36)$.

We observed no significant differences in whether clinicians reported asking about the patient's occupation $(\mathrm{t}[112]=-0.115, \mathrm{p}=0.909$; female patients: $\mathrm{M}=4.25, \mathrm{SD}=0.79$; male patients: $\mathrm{M}=4.23, \mathrm{SD}=0.85$ ), counseling about the chronicity of LBP $(\mathrm{t}[114]=0.621, \mathrm{p}=0.536$; female patients: $\mathrm{M}=3.52$, $\mathrm{SD}=0.93$; male patients: $\mathrm{M}=4.50, \mathrm{SD}=0.87$ ), or scheduling a follow-up visit for LBP after the initial encounter $(\mathrm{t}[114]=-0.198, \mathrm{p}=0.843$; female patients: $\mathrm{M}=3.76, \mathrm{SD}=0.92$; male patients: $\mathrm{M}=3.72, \mathrm{SD}=0.95$ ) based on the patient's gender.

\section{LBP diagnosis}

We observed no significant differences in the diagnoses clinicians reported utilizing for male and female patients presenting with LBP $(\mathrm{p}=1.00)$. For both male and female patients, clinicians most frequently utilized low back pain as the diagnosis $(n=34,60.7 \%)$, followed by lumbosacral muscle strain (female patients: $\mathrm{n}=11,19.6 \%$; male patients: $\mathrm{n}=12,21.4 \%)$, mechanical back pain $(\mathrm{n}=9,15.5 \%)$, “other" (i.e., "postural imbalance”); $\mathrm{n}=1,1.7 \%$ ), and sacroiliac joint dysfunction (female patients: $\mathrm{n}=1,1.7 \%$; male patients: $\mathrm{n}=0,0.0 \%$ ) (Table 2). 
Table 2: What is the most frequent diagnosis used for low back pain?

\begin{tabular}{|c|c|c|c|c|}
\hline \multirow[t]{2}{*}{ Diagnosis } & \multicolumn{2}{|c|}{ Female patients } & \multicolumn{2}{|c|}{ Male patients } \\
\hline & Frequency & Percent & Frequency & Percent \\
\hline Low back pain & 34 & $61 \%$ & 34 & $61 \%$ \\
\hline Other & 22 & $39 \%$ & 22 & $39 \%$ \\
\hline $\begin{array}{l}\text { Lumbosacral muscle } \\
\text { strain }\end{array}$ & 11 & $20 \%$ & 12 & $21 \%$ \\
\hline Mechanical back pain & 9 & $16 \%$ & 9 & $16 \%$ \\
\hline $\begin{array}{l}\text { Sacroiliac joint } \\
\text { dysfunction }\end{array}$ & 1 & $2 \%$ & 0 & $0 \%$ \\
\hline Postural imbalance ${ }^{a}$ & 1 & $2 \%$ & 1 & $2 \%$ \\
\hline
\end{tabular}

${ }^{a}$ Write-in response from respondent.

\section{Discussion}

We are not aware of many similar studies examining primary care attitudes toward LBP in the United States, specifically to explore PCPs' approaches to LBP based on perceived gender role and biological sex differences. Despite evident sex differences in LBP between males and females [32, 33], most providers in our study disagreed that LBP is different clinically between both. This knowledge gap is of substantial importance because LBP is not the only musculoskeletal disorder that is confounded by biological sex factors; hip [34-36] and knee [37, 38] pathologies are among other musculoskeletal disorders impacted by sex differences. It is encouraging, however, to see that providers with either osteopathic or women's health backgrounds were more likely to agree with the role of biological sex in clinical LBP. This may be due to either advanced knowledge or more clinical exposure to females with LBP in their practice. In a systematic review of 15 papers, the doctor's specialty consistently impacted their attitude and beliefs in managing LBP $[39,40]$.

It is concerning that clinicians reported that they did not always ask about pelvic symptoms for patients with LBP, because some pelvic symptoms can indicate severe spinal stenosis, such as loss of control of the bladder or bowel. Clinicians are expected to rule out the worst-case scenario (e.g., cauda equina syndrome). Pelvic symptoms can also impact further evaluation, especially in females whose LBP may be a manifestation of endometriosis [41]. LBP is often associated with pelvic pain during pregnancy and postpartum periods, and the back pain can become recurrent and chronic if the pelvic symptoms are not addressed $[42,43]$.

More than half of the clinicians in our study reported that they did not regularly obtain OBGYN history. In a longitudinal observational study of 219 patients aged
20-69 years old experiencing their first episode of LBP, Washington State PCPs in suburban primary care settings treated over two-thirds of patients with NSAIDs and onethird with muscle relaxants; almost half of the patients were females [44]. With such patterns of prescription, it is of substantial importance to obtain basic OBGYN history from patients to rule out potential conception and explore temporal relationship with dysmenorrhea [45] or parity.

It is evident that pelvic floor muscle strength and exercises contribute to core muscles and spine health $[46,47]$. PCPs in our studies reported that they were more likely to counsel female patients for pelvic floor exercises than males, which could be due to the established relationship between pelvic symptoms and LBP in women of reproductive age or to the plethora of research done on the role of pelvic floor strength in improving women's health and reducing morbidities $[48,49]$. The bias toward counseling pelvic floor exercises for female patients over male patients may need further evaluation, particularly given that most clinicians in our study did not agree that gender has a function in LBP.

PCPs reported that they leaned toward counseling female patients about home chores more than they did male patients, which may be due to the traditional perception of gender roles in our community. Although this may benefit female patients, providers must be mindful of nontraditional gender roles and provide home chore and occupational counseling to both female and male patients.

Clinicians frequently utilized LBP, a nonspecific diagnosis, as the primary diagnosis for their patient encounters. The use of nonspecific LBP for the first episode is expected, yet it requires adequate explanation and education about the causes and potential morbidities of LBP to achieve patient satisfaction and reduce the cost of unnecessary testing [50]. A study in Israel reported noticeable differences between subgroups of PCPs' knowledge of LBP care guidelines [51]; another study in Bahrain suggested that PCPs are not cognizant of the relationship between LBP and disability [52]. The generic diagnosis of "low back pain" could be a reflection of an existing gap in knowledge, approach, and ability to counsel and educate patients about the causes, management, and potential morbidity of LBP. More updated tools can be introduced for triaging nonspecific the first episodes of LBP [53].

\section{Future considerations}

With growing evidence on the biopsychosocial impact of gender on LBP incidence and mortality [54], we aspire that our study draws attention to the importance of bridging the 
potential knowledge gaps by better defining LBP, refining clinical practice guidelines, and maximizing utilization of osteopathic principles and allied healthcare providers. Introducing the potential impact of sex on LBP among other musculoskeletal disorders into medical education may longitudinally improve outcomes for women.

\section{Study limitations}

We were challenged during the pandemic with limited reach to target physicians and reliance on listserv-based email recruitment, resulting in a small sample mostly from an academic setting with potential response bias. Our cross-sectional study design reached to clinicians based in Ohio only at a single point of practice; further qualitative and nationwide evaluation utilizing validated tools and retrospective case reviews are recommended to build on this study to further understand providers' approaches to LBP, explore the knowledge gaps in the impact of biological sex on LBP, and refine current clinical practice guidelines to include patients' preferences and social determinants of health.

\section{Conclusions}

LBP is a global disease caused by several biopsychosocial factors and causes significant morbidity and mortality. Its clinical presentation and impact may differ in female patients compared to males. PCPs are likely to manage the first episode of LBP in the general population, and their understanding of this biological difference is crucial to improve counseling and health outcomes of women. However, this study provides initial evidence that PCPs are not sufficiently knowledgeable about the potential impact of biological sex on LBP presentation, treatment, and management. Further studies to evaluate the knowledge gaps and intervene to bridge them are recommended.

Research funding: None reported.

Author contributions: Both authors provided substantial contributions to conception and design, acquisition of data, or analysis and interpretation of data; both authors drafted the article or revised it critically for important intellectual content; both authors gave final approval of the version of the article to be published; and both authors agree to be accountable for all aspects of the work in ensuring that questions related to the accuracy or integrity of any part of the work are appropriately investigated and resolved.
Competing interests: None reported.

Ethical approval: Our study was deemed exempt from the Ohio State University IRB office (IRB study protocol number: 2020E0500).

Informed consent: All participants were provided written informed consent at the beginning of the online survey.

\section{References}

1. Traeger A, Buchbinder R, Harris I, Maher C. Diagnosis and management of low-back pain in primary care. CMAJ (Can Med Assoc J) 2017;189:E1386-95.

2. Deyo RA, Von Korff M, Duhrkoop D. Opioids for low back pain. BMJ 2015;350:6380.

3. van Tulder M, Koes B, Bombardier C. Low back pain. Best Pract Res Clin Rheumatol 2002;16:761-75.

4. Kent PM, Keating JL. The epidemiology of low back pain in primary care. Chiropr Osteopathy 2005;13. https://doi.org/10.1186/ 1746-1340-13-13.

5. Hartvigsen J, Hancock MJ, Kongsted A, Louw Q, Ferreira ML, Genevay $S$, et al. What low back pain is and why we need to pay attention. Lancet 2018;391:2356-67.

6. Lidgren L. Editorials - the bone and joint decade 2000-2010. Bull World Health Organ 2003;81:62.

7. Chen S, Chen M, Wu X, Lin S, Tao C, Cao H, et al. Global, regional and national burden of low back pain 1990-2019: a systematic analysis of the global burden of disease study 2019. J Orthop Translat 2021;32:49-58.

8. Buchbinder R, Blyth FM, March LM, Brooks P, Woolf AD, Hoy DG. Placing the global burden of low back pain in context. Best Pract Res Clin Rheumatol 2013;27:575-89.

9. Ardakani EM, Leboeuf-Yde C, Walker BF. Failure to define low back pain as a disease or an episode renders research on causality unsuitable: results of a systematic review. Chiropr Man Ther 2018;26. https://doi.org/10.1186/s12998-017-0172-9.

10. Hoy D, Brooks P, Blyth F, Buchbinder R. The epidemiology of low back pain. Best Pract Res Clin Rheumatol 2010;24: 769-81.

11. van Tulder MW, Tuut M, Pennick V, Bombardier C, Assendelft WJ. Quality of primary care guidelines for acute low back pain. Spine 2004;29:E357-62.

12. Stamm TA, Boesendorfer A, Omara M, Ritschl V, Siniša Š, Mosor E. Outcomes research in non-specific low back pain: knowledge transfer in clinical practice. Wien Klin Wochenschr 2019;131: 550-7.

13. Fullen BM, Baxter GD, O'Donovan BG, Doody C, Daly LE, Hurley DA. Factors impacting on doctors' management of acute low back pain: a systematic review. Eur J Pain 2009;13:908-14.

14. Lin I, Wiles L, Waller R, Goucke R, Nagree Y, Gibberd M, et al. What does best practice care for musculoskeletal pain look like? eleven consistent recommendations from high-quality clinical practice guidelines: systematic review. Br J Sports Med 2020; 54:79-86.

15. Wijnhoven HAH, de Vet HCW, Smit HA, Picavet HSJ. Hormonal and reproductive factors are associated with chronic low back pain and chronic upper extremity pain in women - the morgen study. Spine 2006;31:1496-502. 
16. Chenot JF, Becker A, Leonhardt C, Keller S, Donner-Banzhoff N, Hildebrandt J, et al. Sex differences in presentation, course, and management of low back pain in primary care. Clin J Pain 2008; 24:578-84.

17. Scheele J, Enthoven WT, Bierma-Zeinstra SM, Peul WC, van Tulder MW, Bohnen AM, et al. Characteristics of older patients with back pain in general practice: BACE cohort study: characteristics of older patients with back pain. Eur J Pain 2014;18:279-87.

18. Meints SM, Wang V, Edwards RR. Sex and race differences in pain sensitization among patients with chronic low back pain. J Pain 2018;19:1461-70.

19. Karran EL, Grant AR, Moseley GL. Low back pain and the social determinants of health: a systematic review and narrative synthesis. Pain 2020;161:2476-93.

20. Diz JBM, de Souza Moreira B, Felício DC, Teixeira LF, de JesusMoraleida FR, de Queiroz BZ, et al. Brain-derived neurotrophic factor plasma levels are increased in older women after an acute episode of low back pain. Arch Gerontol Geriatr 2017;71: 75-82.

21. de Castro JBP, Lima VP, Santos AOB, Silva GCPSM, Oliveira JGM, Silva JNL, et al. Correlation analysis between biochemical markers, pain perception, low back functional disability, and muscle strength in postmenopausal women with low back pain. J Phys Educ Sport 2020;20:24-30.

22. Bernardes SF, Silva SA, Carvalho H, Costa M, Pereira S. Is it a (fe) male pain? Portuguese nurses' and laypeople's gendered representations of common pains. Eur J Pain 2014;18:530-9.

23. Arab AM, Behbahani RB, Lorestani L, Azari A. Assessment of pelvic floor muscle function in women with and without low back pain using transabdominal ultrasound. Man Ther 2010;15:235-9.

24. Taguchi T. Low back pain in young and middle-aged people. Japan Med Assoc J 2003;46:417-23.

25. Sheffer CE, Cassisi JE, Ferraresi LM, Lofland KR, McCracken LM. Sex differences in the presentation of chronic low back pain. Psychol Women Q 2002;26:329-40.

26. Sinclair M, Close C, McCullough JE, Hughes C, Liddle SD. How do women manage pregnancy-related low back and/or pelvic pain? descriptive findings from an online survey. Evid base Midwifery 2014;12:76-82.

27. Innes S, Jacques A, Scott K, Walker B. Early age at menarche is associated with post-menarche back pain: an analysis of the Raine study. Eur J Pain 2021;25:2155-65.

28. Pierce H, Homer CSE, Dahlen HG, King J. Pregnancy-related lumbopelvic pain: listening to Australian women. Nurs Res Pract; 2012;2012:387428.

29. Wellock VK, Crichton MA. Symphysis pubis dysfunction: women's experiences of care. Br J Midwifery 2007;15:494-9.

30. Pincus T, Kent P, Bronfort G, Loisel P, Pransky G, Hartvigsen J. Twenty-five years with the biopsychosocial model of low back pain-is it time to celebrate? a report from the twelfth international forum for primary care research on low back pain. Spine 2013;38: 2118-23.

31. Gullattee AC. Non-discogenic low back pain in females. J Natl Med Assoc 1976;68:51-13.

32. Alonso-García M, Sarría-Santamera A. The economic and social burden of low back pain in Spain: a national assessment of the economic and social impact of low back pain in Spain. Spine 2020;45:1032.
33. Ono R, Higashi T, Takahashi O, Tokuda Y, Shimbo T, Endo H, et al. Sex differences in the change in health-related quality of life associated with low back pain. Qual Life Res 2012;21:1705-11.

34. Wijnhoven HAH, de Vet HCW, Picavet HSJ. Explaining sex differences in chronic musculoskeletal pain in a general population. Pain 2006;124:158-66.

35. Hetsroni I, Dela Torre K, Duke G, Lyman S, Kelly BT. Sex differences of hip morphology in young adults with hip pain and labral tears. Arthroscopy 2013;29:54-63.

36. Peng YL, Tenan MS, Griffin L. Hip position and sex differences in motor unit firing patterns of the vastus medialis and vastus medialis oblique in healthy individuals. J Appl Physiol 2018;124: 1438-46.

37. Tenan MS, Peng YL, Hackney AC, Griffin L. Menstrual cycle mediates vastus medialis and vastus medialis oblique muscle activity. Med Sci Sports Exerc 2013;45:2151-7.

38. Behan FP, Maden-Wilkinson TM, Pain MTG, Folland JP. Sex differences in muscle morphology of the knee flexors and knee extensors. PLoS One 2018;13. https://doi.org/10.1371/journal. pone.0190903.

39. Sinclair J, Selfe J. Sex differences in knee loading in recreational runners. J Biomech 2015;48:2171-5.

40. Fullen BM, Baxter GD, O'Donovan BGG, Doody C, Daly L, Hurley DA. Doctors' attitudes and beliefs regarding acute low back pain management: a systematic review. Pain 2008;136:388-96.

41. Braeuninger-Weimer K, Rooslien H, Anjarwalla N, Pincus T. Reassurance and healthcare seeking in people with persistent musculoskeletal low back pain consulting orthopaedic spine practitioners: a prospective cohort study. Eur J Pain 2021;25: 1540-50.

42. Dongxu Z, Fei Y, Xing X, Bo-Yin Z, Qingsan Z. Low back pain tied to spinal endometriosis. Eur Spine J 2014;23:214-7.

43. Algudairi G, Aleisa E, Al-Badr A. Prevalence of neuropathic pain and pelvic floor disorders among females seeking physical therapy for chronic low back pain. Urol Ann 2019;11:20-6.

44. Cherkin DC, Wheeler KJ, Barlow W, Deyo RA. Medication use for low back pain in primary care. Spine 1998;23:607-14.

45. Boesler D, Warner M, Alpers A, Finnerty EP, Kilmore MA. Efficacy of high-velocity low-amplitude manipulative technique in subjects with low-back pain during menstrual cramping. J Am Osteopath Assoc 1993;93:203-8.

46. Bi X, Zhao J, Zhao L, Liu Z, Zhang J, Sun D, et al. Pelvic floor muscle exercise for chronic low back pain. J Int Med Res 2013; 41:146-52.

47. Ghaderi F, Mohammadi K, Amir Sasan R, Niko Kheslat S, Oskouei AE. Effects of stabilization exercises focusing on pelvic floor muscles on low back pain and urinary incontinence in women. Urology 2016;93:50-4.

48. Mohseni-Bandpei MA, Rahmani N, Behtash H, Karimloo M. The effect of pelvic floor muscle exercise on women with chronic nonspecific low back pain. J Bodyw Mov Ther 2011;15:75-81.

49. Mørkved S, Bø K, Schei B, Salvesen KA. Pelvic floor muscle training during pregnancy to prevent urinary incontinence: $a$ single-blind randomized controlled trial. Obstet Gynecol 2003; 101:313-9.

50. Godfrey JR, Dugan SA. Toward optimal health: advances in chronic back pain management for women. J Womens Health 2009;18:1533-7. 
51. Dahan R, Reis S, Borkan J, Brown JB, Hermoni D, Mansor N, et al. Is knowledge a barrier to implementing low back pain guidelines? Assessing the knowledge of Israeli family doctors. J Eval Clin Pract 2008;14:785-91.

52. Wasif P, Alsammak E, Sorinola I, Trinidad P, Critchley DJ. Attitudes and beliefs of healthcare providers towards low back pain in Bahrain. Physiotherapy 2020;107:153.
53. Bardin LD, King P, Maher CG. Diagnostic triage for low back pain: a practical approach for primary care. Med J Aust 2017;206: 268-73.

54. Roseen EJ, Rajendran I, Stein P, Fredman L, Fink HA, LaValley MP, et al. Association of back pain with mortality: a systematic review and meta-analysis of cohort studies. J Gen Intern Med 2021;36: 3148-58. 